\title{
Experimental Study on Interface Strength Between Hardened Cement Paste-Aggregate
}

\author{
Wenliang Han ${ }^{1,2}$, Hongfa Yu ${ }^{1,2, *}$, Haiyan $\mathrm{Ma}^{1,2}$ \\ ${ }^{1}$ Civil Aviation College, Nanjing University of Aeronautics and Astronautics, Nanjing, China \\ ${ }^{2}$ Jiangsu Airport Infrastructure Safety Engineering Research Center, Nanjing, China
}

Email address:

Hanwenliang929@163.com (Wenliang Han), yuhongfa@nuaa.edu.cn (Hongfa Yu), haiyanma@nuaa.edu.cn (Haiyan Ma)

*Corresponding author

\section{To cite this article:}

Wenliang Han, Hongfa Yu, Haiyan Ma. Experimental Study on Interface Strength Between Hardened Cement Paste-Aggregate. American Journal of Civil Engineering. Vol. 9, No. 2, 2021, pp. 47-54. doi: 10.11648/j.ajce.20210902.13

Received: March 9, 2021; Accepted: April 9, 2021; Published: April 26, 2021

\begin{abstract}
The interfacial transition zone (ITZ) is a weak part of concrete, which is the main reason that the mechanical properties of concrete are far lower than those of hardened cement paste and aggregate itself. In order to improve the mechanical properties of concrete ITZ, the effects of cement varieties, water-binder ratio, mineral admixtures and aggregate types on the strength of hardened cement paste-aggregate ITZ were studied by orthogonal test. A linear regression model between interfacial bonding splitting tensile strength and splitting tensile strength of hardened cement paste was proposed. The results show that the water-binder ratio has the greatest impact on the mechanical properties of ITZ, followed by aggregate. The interfacial bonding splitting tensile strength of five kinds of aggregate and cement paste is in the order of marble $>$ coral $>$ granite $>$ basalt $>$ quartzite. The optimal interface test combination is as follows: water-binder ratio 0.25 , aggregate is marble, $\mathrm{P} \cdot \mathrm{O} 52.5$ cement, slag content $15 \%$, fly ash content $20 \%$ and silica fume content $10 \%$. The optimal cement slurry combination is: water-cement ratio 0.25 , basic magnesium sulfate cement, slag content $15 \%$, fly ash content $20 \%$ and silica fume content $10 \%$. The linear regression model between interfacial bond splitting tensile strength and hardened cement paste splitting tensile strength is established by dividing aggregate, which is of great significance to study the law of interfacial strength.
\end{abstract}

Keywords: Interfacial Transition Zone, Interfacial Bonding Splitting Tensile Strength, Orthogonal Test, Range Analysis

\section{Introduction}

Concrete is a kind of building material with uneven, extremely complex and obvious differences in the composition of various internal components. Micromechanical model divides hard concrete structure into three parts: hardened cement paste phase, aggregate and interface transition zone (ITZ) formed between them [1]. ITZ is a weak link in concrete, and the damage and failure of concrete are largely attributed to the gradual destruction of ITZ structure [2].

At present, the strength test methods of ITZ include direct method and indirect method [3]. The direct method uses the depth sensing micro indentation method to directly measure the elastic modulus of ITZ, which is rarely used because of its difficulty in preparation and testing [4]. Indirect method is generally through the "containing interface specimen" to determine ITZ interface bonding tensile strength, interface bonding splitting tensile strength [5-7]. Domestic and foreign scholars mostly adopt indirect method to study the mechanical properties of interface. Zhou et al. found that the interfacial bonding strength of concrete decreased with the increase of water-cement ratio [8]. Wang found that the addition of fly ash would reduce the thickness of ITZ, so the interfacial bonding splitting tensile strength was higher than that of concrete without fly ash [9]. Zhang found that the mechanical properties of concrete using different types of aggregates were different, and the concrete strength of each aggregate was granite $\approx$ basalt $>$ marble [10].

At present, there have been a large number of literature on the micro-properties of ITZ [11-13]. However, due to the difficulty in testing the strength characteristics of ITZ, there are few macro-mechanical data of ITZ. In this paper, in order 
to establish the ITZ interface mechanical properties database of common concrete, orthogonal design was used to systematically study the influence of cement varieties, water-binder ratio, types and contents of admixtures and aggregate types on ITZ strength, so as to determine the key factors of interface strength, and establish the relationship between interface strength and hardened cement paste strength.

\section{Experiment}

\subsection{Mix Proportion Design of Orthogonal Test}

In order to explore the influence of cementitious materials, water-binder ratio and aggregate types on the interfacial strength of hardened cement paste-aggregate, and to obtain the optimal mix proportion of the strength of the interface test specimen. Six factors including cement type, water-binder ratio, mineral admixture type and its dosage, and aggregate type were studied, and five levels were selected for each factor. The $\mathrm{L}_{25}\left(5^{6}\right)$ orthogonal table was used to arrange the experiment, and the factor-level table is shown in Table 1. In order to ensure the total quality of cementitious materials unchanged, the mineral admixture content is cement replacement rate. The mix proportion orthogonal design test plan sees Table 2, the mix proportion orthogonal design sees Table 3.

The orthogonal test index of the interface test specimen is the interfacial bonding splitting tensile strength. In order to establish the relationship between the interfacial bonding splitting tensile strength and the strength of cement paste, the cement paste mixture ratio with the same proportion of cementitious materials as the interface test specimen is designed, and a new orthogonal table is formed. The factor B of the orthogonal table is an empty column, and the specimen index is the splitting tensile strength.

Table 1. Factor level table of hardened cement paste-aggregate interface test.

\begin{tabular}{lllllll}
\hline \multirow{2}{*}{ Level } & Factor & & & & & \\
\cline { 2 - 7 } & A (Cement) & B (Aggregate) & C (W/B) & D FA/\% $/ \%$ & 0 & F SF/\% \\
\hline 1 & P·I 52.5 & Coral & 0.25 & 0 & 15 & 0 \\
2 & P.O 52.5 & Granite & 0.33 & 10 & 25 & 5 \\
3 & P·II 52.5 & Basalt & 0.40 & 15 & 35 & 10 \\
4 & P.O 42.5 & Marble & 0.48 & 20 & 45 & 15 \\
5 & BMSC & Quartzite & 0.55 & 25 & 5 \\
\hline
\end{tabular}

Note: The "BMSC" in the table is basic magnesium sulfate cement.

Table 2. Table of orthogonal test scheme for hardened cement paste-aggregate interface test piece.

\begin{tabular}{|c|c|c|c|c|c|c|}
\hline Number & A (Cement) & B (Aggregate) & $\mathrm{C}(\mathrm{W} / \mathrm{B})$ & D FA $/ \%$ & E SG/\% & F SF $/ \%$ \\
\hline $1 \#$ & 1(P·I 52.5) & 1(Coral) & $2(0.33)$ & $4(20)$ & $3(25)$ & $2(5)$ \\
\hline $2 \#$ & $2(\mathrm{P} \cdot \mathrm{O} 52.5)$ & 1(Coral) & $5(0.55)$ & $5(25)$ & $5(45)$ & $4(15)$ \\
\hline $4 \#$ & $4(\mathrm{P} \cdot \mathrm{O} 42.5)$ & 1(Coral) & $1(0.25)$ & $3(15)$ & $1(0)$ & $3(10)$ \\
\hline $5 \#$ & 5(BMSC) & 1(Coral) & $3(0.40)$ & $2(10)$ & $2(15)$ & $5(5)$ \\
\hline $6 \#$ & 1(P·I 52.5) & 2(Granite) & $3(0.40)$ & $3(15)$ & $4(35)$ & $4(15)$ \\
\hline $7 \#$ & $2(\mathrm{P} \cdot \mathrm{O} 52.5)$ & 2(Granite) & $2(0.33)$ & $2(10)$ & $1(0)$ & $1(0)$ \\
\hline $8 \#$ & 3(P·II 52.5) & 2(Granite) & $5(0.55)$ & $4(20)$ & $2(15)$ & $3(10)$ \\
\hline 9\# & $4(\mathrm{P} \cdot \mathrm{O} 42.5)$ & 2(Granite) & $4(0.48)$ & $5(25)$ & $3(25)$ & $5(5)$ \\
\hline $10 \#$ & 5(BMSC) & 2(Granite) & $1(0.25)$ & $1(0)$ & $5(45)$ & $2(5)$ \\
\hline $11 \#$ & 1(P·I 52.5) & 3(Basalt) & $1(0.25)$ & $5(25)$ & $2(15)$ & $1(0)$ \\
\hline $12 \#$ & $2(\mathrm{P} \cdot \mathrm{O} 52.5)$ & 3(Basalt) & $3(0.40)$ & $1(0)$ & $3(25)$ & $3(10)$ \\
\hline $13 \#$ & 3(P·II 52.5) & 3(Basalt) & $2(0.33)$ & $3(15)$ & $5(45)$ & $5(5)$ \\
\hline $15 \#$ & 5(BMSC) & 3(Basalt) & $4(0.48)$ & $4(20)$ & $1(0)$ & $4(15)$ \\
\hline $16 \#$ & 1(P.I 52.5) & 4(Marble) & $4(0.48)$ & $2(10)$ & $5(45)$ & $3(10)$ \\
\hline $17 \#$ & $2(\mathrm{P} \cdot \mathrm{O} 52.5)$ & 4(Marble) & $1(0.25)$ & $4(20)$ & $4(35)$ & $5(5)$ \\
\hline $18 \#$ & 3(P.II 52.5) & 4(Marble) & $3(0.40)$ & $5(25)$ & $1(0)$ & $2(5)$ \\
\hline $19 \#$ & $4(\mathrm{P} \cdot \mathrm{O} 42.5)$ & 4(Marble) & $2(0.33)$ & $1(0)$ & $2(15)$ & $4(15)$ \\
\hline $20 \#$ & 5(BMSC) & 4(Marble) & $5(0.55)$ & $3(15)$ & $3(25)$ & $1(0)$ \\
\hline $21 \#$ & 1(P·I 52.5) & 5(Quartzite) & $5(0.55)$ & $1(0)$ & $1(0)$ & $5(5)$ \\
\hline $22 \#$ & $2(\mathrm{P} \cdot \mathrm{O} 52.5)$ & 5(Quartzite) & $4(0.48)$ & $3(15)$ & $2(15)$ & $2(5)$ \\
\hline $23 \#$ & 3(P·II 52.5) & 5(Quartzite) & $1(0.25)$ & $2(10)$ & $3(25)$ & $4(15)$ \\
\hline $24 \#$ & $4(\mathrm{P} \cdot \mathrm{O} 42.5)$ & 5(Quartzite) & $3(0.40)$ & $4(20)$ & $4(35)$ & $1(0)$ \\
\hline $25 \#$ & 5(BMSC) & 5(Quartzite) & $2(0.33)$ & $5(25)$ & $5(45)$ & $3(10)$ \\
\hline
\end{tabular}


Table 3. Mix ratio of hardened cement paste-aggregate interface/g.

\begin{tabular}{|c|c|c|c|c|c|c|c|c|}
\hline \multirow{2}{*}{ Number } & \multicolumn{2}{|l|}{ Cement } & \multirow{2}{*}{ Aggregate } & \multirow{2}{*}{ Water } & \multirow{2}{*}{ FA } & \multirow{2}{*}{ SG } & \multirow{2}{*}{ SF } & \multirow{2}{*}{$\begin{array}{l}\text { water reducing } \\
\text { admixture }\end{array}$} \\
\hline & Type & Content & & & & & & \\
\hline $1 \#$ & P.I 52.5 & 800 & Coral & 528 & 320 & 400 & 80 & 4 \\
\hline $2 \#$ & P.O 52.5 & 240 & Coral & 880 & 400 & 720 & 240 & 0 \\
\hline $3 \#$ & P.II 52.5 & 1040 & Coral & 768 & 0 & 560 & 0 & 0 \\
\hline $4 \#$ & $\mathrm{P} \cdot \mathrm{O} 42.5$ & 1200 & Coral & 400 & 240 & 0 & 160 & 7 \\
\hline $5 \#$ & BMSC & 1120 & Coral & 640 & 160 & 240 & 80 & 0 \\
\hline $6 \#$ & P.I 52.5 & 560 & Granite & 640 & 240 & 560 & 240 & 0 \\
\hline $7 \#$ & P.O 52.5 & 1440 & Granite & 528 & 160 & 0 & 0 & 4 \\
\hline $8 \#$ & P.II 52.5 & 880 & Granite & 880 & 320 & 240 & 160 & 0 \\
\hline 9\# & $\mathrm{P} \cdot \mathrm{O} 42.5$ & 720 & Granite & 768 & 400 & 400 & 80 & 0 \\
\hline $10 \#$ & BMSC & 800 & Granite & 400 & 0 & 720 & 80 & 7 \\
\hline $11 \#$ & P.I 52.5 & 960 & Basalt & 400 & 400 & 240 & 0 & 7 \\
\hline $12 \#$ & P.O 52.5 & 1040 & Basalt & 640 & 0 & 400 & 160 & 0 \\
\hline $13 \#$ & P.II 52.5 & 560 & Basalt & 528 & 240 & 720 & 80 & 4 \\
\hline $14 \#$ & $\mathrm{P} \cdot \mathrm{O} 42.5$ & 800 & Basalt & 880 & 160 & 560 & 80 & 0 \\
\hline $15 \#$ & BMSC & 1040 & Basalt & 768 & 320 & 0 & 240 & 0 \\
\hline $16 \#$ & P.I 52.5 & 560 & Marble & 768 & 160 & 720 & 160 & 0 \\
\hline $17 \#$ & $\mathrm{P} \cdot \mathrm{O} 52.5$ & 640 & Marble & 400 & 320 & 560 & 80 & 7 \\
\hline $18 \#$ & P.II 52.5 & 1120 & Marble & 640 & 400 & 0 & 80 & 0 \\
\hline $19 \#$ & $\mathrm{P} \cdot \mathrm{O} 42.5$ & 1120 & Marble & 528 & 0 & 240 & 240 & 4 \\
\hline $20 \#$ & BMSC & 960 & Marble & 880 & 240 & 400 & 0 & 0 \\
\hline $21 \#$ & P.I 52.5 & 1520 & Quartzite & 880 & 0 & 0 & 80 & 0 \\
\hline $22 \#$ & P.O 52.5 & 1040 & Quartzite & 768 & 240 & 240 & 80 & 0 \\
\hline $23 \#$ & P.II 52.5 & 800 & Quartzite & 400 & 160 & 400 & 240 & 7 \\
\hline $24 \#$ & $\mathrm{P} \cdot \mathrm{O} 42.5$ & 720 & Quartzite & 640 & 320 & 560 & 0 & 0 \\
\hline $25 \#$ & BMSC & 320 & Quartzite & 528 & 400 & 720 & 160 & 4 \\
\hline
\end{tabular}

Note: Ordinary cement uses polycarboxylate superplasticizer, BMSC uses naphthalene superplasticizer.

\subsection{Material}

(1) Cementitious materials

Cement: P.I 52.5 cement produced by Shandong Cement Factory Co., Ltd.; P.O 42.5 cement produced by Nanjing Hailuo Cement Co., Ltd.; P.O 52.5 cement produced by Zhucheng Yangchun Cement Co., Ltd.; P.II 52.5 cement produced by Jiangnan Xiaoyetian Cement Plant in Qixia District, Nanjing City; BMSC is prepared by mixing magnesite calcined light-burned magnesium oxide powder $(\mathrm{MgO})$ of Liaoning Huafeng Magnesium Industry Co., Ltd. and magnesium sulfate heptahydrate (industrial grade, $\mathrm{MgSO}_{4} \cdot 7 \mathrm{H}_{2} \mathrm{O}$ ) of Shandong Yongxin Chemical Co., Ltd. with chemical admixtures in a certain proportion. The chemical composition of the main materials of BMSC is shown in Table 4. The chemical composition of other cements is shown in Table 5. Physical properties of five cements are shown in Table 6.

Table 4. Chemical composition of basic magnesium sulfate cement raw materials $1 \%$.

\begin{tabular}{llllllllllll}
\hline Material & $\mathbf{M g}^{2+}$ & $\mathbf{S O}_{4}^{2-}$ & $\mathbf{C a}^{2+}$ & $\mathbf{S i O}_{2}$ & $\mathbf{A l}_{2} \mathbf{O}_{3}$ & $\mathbf{F e}_{2} \mathbf{O}_{3}$ & $\mathbf{C a O}$ & $\mathbf{M g O}$ & $\mathbf{S O}_{3}$ & $\mathbf{N a}_{2} \mathbf{O}$ & Loss of ignition \\
\hline $\mathrm{MgSO}_{4} \cdot 7 \mathrm{H}_{2} \mathrm{O}$ & 9.73 & 40.06 & 0.03 & - & - & - & - & - & - & - & 50.18 \\
$\mathrm{MgO}$ & - & - & - & 0.34 & 0.23 & 0.55 & 1.98 & 0.51 & 0.37 & 0.74 & 15.16 \\
\hline
\end{tabular}

Table 5. Chemical composition of cement $/ \%$.

\begin{tabular}{|c|c|c|c|c|c|c|c|}
\hline Cement & $\mathrm{SiO}_{2}$ & $\mathrm{Al}_{2} \mathrm{O}_{3}$ & $\mathrm{Fe}_{2} \mathrm{O}_{3}$ & $\mathrm{CaO}$ & MgO & $\mathrm{SO}_{3}$ & $\mathrm{~K}_{2} \mathrm{O}$ \\
\hline P.I 52.5 & 21.96 & 6.51 & 3.56 & 63.57 & 0.14 & 3.67 & 0.59 \\
\hline P.O 52.5 & 26.77 & 7.97 & 3.05 & 57.14 & 1.72 & 2.6 & 0.75 \\
\hline P.II 52.5 & 22.23 & 4.78 & 3.06 & 66.33 & 0.83 & 2.16 & 0.61 \\
\hline $\mathrm{P} \cdot \mathrm{O} 42.5$ & 24.12 & 6.89 & 3.36 & 59.04 & 2.78 & 3.16 & 0.65 \\
\hline
\end{tabular}

Table 6. Tables of cement physical properties.

\begin{tabular}{llllll}
\hline \multirow{2}{*}{ Cement } & Setting time /min & & Flexural strength /MPa & \multicolumn{2}{c}{ compressive strength /MPa } \\
\cline { 2 - 6 } & Initial & Final & 3d & 28d & 3d \\
\hline P.I 52.5 & 160 & 230 & 6.1 & 8.4 & 32.7 \\
P.O 52.5 & 142 & 251 & 6.2 & 5.7 & 33.5 \\
P.II 52.5 & 120 & 173 & 6.5 & 9.1 & 36.8 \\
P.O 42.5 & 215 & 265 & 5.5 & 8.6 & 26.3 \\
BMSC & 115 & 282 & 7.8 & 14.5 & 59.4 \\
\hline
\end{tabular}

Mineral admixtures: Grade I fly ash (FA) produced by Nanjing Electric Power Plant; S95 grade grinding slag (SG) 
with specific surface area of $415 \mathrm{~m}^{2} / \mathrm{kg}$ was used in the production and processing of Jiangnan Grinding Company. Silica Fume (SF) is produced by Erken Silicone (Shanghai)
Co., Ltd., its $\mathrm{SiO}_{2}$ content is more than $90 \%$ and its specific surface area is $20 \mathrm{~m}^{2} / \mathrm{kg}$. The chemical compositions of mineral admixtures are shown in Table 7.

Table 7. Chemical constituents of mineral admixtures $/ \%$.

\begin{tabular}{llllllll}
\hline Mineral admixtures & $\mathbf{S i O}_{\mathbf{2}}$ & $\mathbf{A l}_{\mathbf{2}} \mathbf{O}_{\mathbf{3}}$ & $\mathbf{F e}_{\mathbf{2}} \mathbf{O}_{\mathbf{3}}$ & $\mathbf{C a O}$ & $\mathbf{M g O}$ & $\mathbf{S O}_{\mathbf{3}}$ & $\mathbf{K}_{\mathbf{2}} \mathbf{O}$ \\
\hline FA & 56.71 & 25.08 & 7.35 & 5.42 & 1.63 & 1.07 & 0.67 \\
SG & 33.31 & 14.34 & 1.61 & 38.87 & 9.97 & 0.87 & 0.64 \\
SF & 92.88 & 0.97 & 1.48 & 1.64 & 1.37 & 0.39 & 1.17 \\
\hline
\end{tabular}

(2) Water: Use of tap water in Nanjing in line with national standards

\section{(3) Aggregate}

The coral is transported back from Nansha Islands in South China Sea. The measured uniaxial compressive cube strength is $82 \mathrm{MPa}$ and the roughness is $2.024 \mu \mathrm{m}$, as shown in Figure 1(a). The granite is produced in Fuzhou, Fujian Province. The measured uniaxial compressive cube strength is $251 \mathrm{MPa}$ and the roughness is $1.69 \mu \mathrm{m}$, as shown in Figure 1(b). The origin

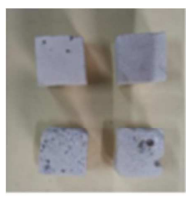

(a) Coral

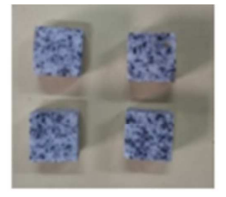

(b) Granite

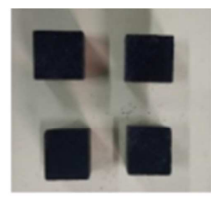

(c) Basalt of basalt is Fuding, Fujian Province. The measured uniaxial compressive cube strength is $147 \mathrm{MPa}$ and the roughness is $2.115 \mu \mathrm{m}$, as shown in Figure 1(c). Marble is produced in Liuzhou, Guangxi. The measured uniaxial compressive cube strength is $111 \mathrm{MPa}$ and the roughness is $2.512 \mu \mathrm{m}$, as shown in Figure 1(d). The origin of quartzite is Wuxue, Hubei. The measured uniaxial compressive cube strength is $223 \mathrm{MPa}$, and the roughness is $1.407 \mu \mathrm{m}$. As shown in Figure 1(e).

Figure 1. Standard specimen of aggregate.

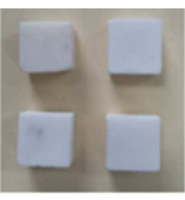

(d) Marble

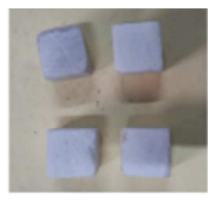

(e) Quartzite
(4) Water reducing agent

Polycarboxylate high performance water reducer: Jiangsu Subote New Materials Co., Ltd., model: SW-A, dosage 1.0\%, density $1.044 \mathrm{~g} / \mathrm{mL}$, PH 5.5, chloride content $0 \%$, total alkali content $1.02 \%$, water reduction rate $26.3 \%$, gas content $2.0 \%$, suitable for ordinary Portland cement and Portland cement;

Naphthalene series superplasticizer: Jiangsu Subote New Materials Co., Ltd. Production, performance in line with GB8076, water reduction rate up to $25 \%$, used for BMSC.

\subsection{Sample Preparation and Test Method}

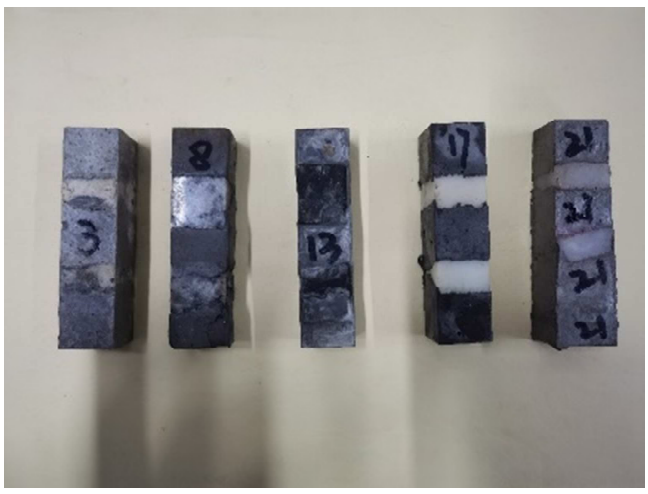

Figure 2. Standard interface.

According to Table 3, 16 standard interface specimens with $20 \mathrm{~mm} \times 20 \mathrm{~mm} \times 80 \mathrm{~mm}$ cement paste and aggregate alternately arranged were poured in each mix proportion (as shown in Figure 2) to measure the bonding splitting tensile strength of $3 \mathrm{~d}, 7 \mathrm{~d}, 14 \mathrm{~d}$ and $28 \mathrm{~d}$ interface specimens. According to the mix proportion design of cement paste orthogonal test, 16 cube cement paste specimens of $20 \mathrm{~mm} \times 20 \mathrm{~mm} \times 20 \mathrm{~mm}$ were poured in each mix proportion for measuring the splitting tensile strength of $3 \mathrm{~d}, 7 \mathrm{~d}, 14 \mathrm{~d}$ and $28 \mathrm{~d}$.

The strength test adopts HG-YH100D press machine of Jiangsu Zhuoheng Measurement and Control Technology Co., Ltd (as shown in Figure 3). The test force range is $100 \mathrm{kN} / 5$ $\mathrm{kN}$, and the test sensitivity is $0.01 \mathrm{kN}$.

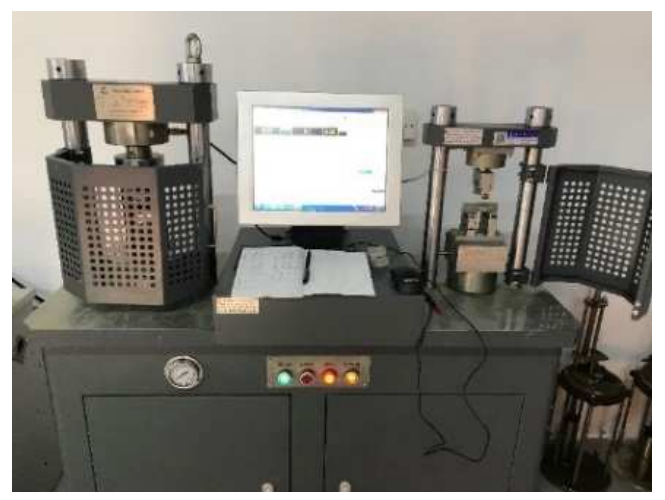

Figure 3. Press machine.

\section{Range Analysis of Orthogonal Test Results}

When the age is $28 \mathrm{~d}$, the orthogonal test results of the splitting tensile strength of cement paste and the bonding splitting tensile strength of interface test pieces are shown in Table 8 . 
Table 8. Mechanical properties of $28 \mathrm{~d}$ orthogonal test.

\begin{tabular}{lll}
\hline Number & Splitting tensile strength of cement paste /MPa & Bond splitting tensile strength of interface test pieces $/ \mathbf{M P a}$ \\
\hline $1 \#$ & 7.99 & 5.84 \\
$2 \#$ & 4.12 & 3.42 \\
$3 \#$ & 6.09 & 3.91 \\
$4 \#$ & 10.06 & 6.18 \\
$5 \#$ & 8.67 & 5.18 \\
$6 \#$ & 7.62 & 4.17 \\
$7 \#$ & 9.15 & 5.58 \\
$8 \#$ & 6.86 & 4.70 \\
$9 \#$ & 6.11 & 3.94 \\
$10 \#$ & 9.98 & 5.87 \\
$11 \#$ & 9.46 & 6.36 \\
$12 \#$ & 7.85 & 5.27 \\
$13 \#$ & 8.60 & 4.32 \\
$14 \#$ & 5.98 & 2.85 \\
$15 \#$ & 9.14 & 4.86 \\
$16 \#$ & 5.96 & 4.39 \\
$17 \#$ & 9.33 & 7.22 \\
$18 \#$ & 6.98 & 4.76 \\
$19 \#$ & 8.73 & 6.27 \\
$20 \#$ & 5.96 & 4.39 \\
$21 \#$ & 5.27 & 2.08 \\
$22 \#$ & 7.04 & 4.93 \\
$23 \#$ & 8.40 & 5.48 \\
$24 \#$ & 7.22 & 3.96 \\
$25 \#$ & 7.41 & 4.87 \\
\hline
\end{tabular}

\subsection{Range Analysis of Orthogonal Test Results of Cement Paste Specimens}

The range method is used to determine the influence of various factors on the $28 \mathrm{~d}$ splitting tensile strength test results of hardened cement paste [14]. The range analysis results are shown in Table 9. The relationship between the level of various factors and the $28 \mathrm{~d}$ splitting tensile strength of hardened cement paste is shown in Figure 4.

The $\mathrm{k}_{1}, \mathrm{k}_{2}, \mathrm{k}_{3}, \mathrm{k}_{4}, \mathrm{k}$ and range of $28 \mathrm{~d}$ splitting tensile strength of hardened cement paste at different levels given in Table 9 show that the splitting tensile strength of $4 \#$ is the highest, which is $10.06 \mathrm{MPa}$. The cement variety is $\mathrm{P} \cdot \mathrm{O} 42.5$ cement, the water-binder ratio is 0.25 , the fly ash content is $15 \%$, the slag content is $0 \%$, and the silica fume content is $10 \%$. Among them, the range $\mathrm{R}_{\mathrm{C}}(3.82 \mathrm{MPa})$ of water-cement ratio and $\mathrm{R}_{\mathrm{D}}(1.29 \mathrm{MPa})$ of fly ash content are greater than the range $R_{B}(1.14 \mathrm{MPa})$ of empty column, indicating that the water-binder ratio and fly ash content of hardened cement paste have a significant effect on the splitting tensile strength of hardened cement paste, while the range $\mathrm{R}_{\mathrm{A}}(0.98 \mathrm{MPa}), \mathrm{R}_{\mathrm{E}}$ $(0.92 \mathrm{MPa})$ and $\mathrm{R}_{\mathrm{F}}(0.05 \mathrm{MPa})$ of cement varieties, slag content and silica fume content are less than those of $R_{B}(1.14 \mathrm{MPa})$, indicating that the cement varieties, slag content and silica fume content of hardened cement paste have little effect on the splitting tensile strength of hardened cement paste.

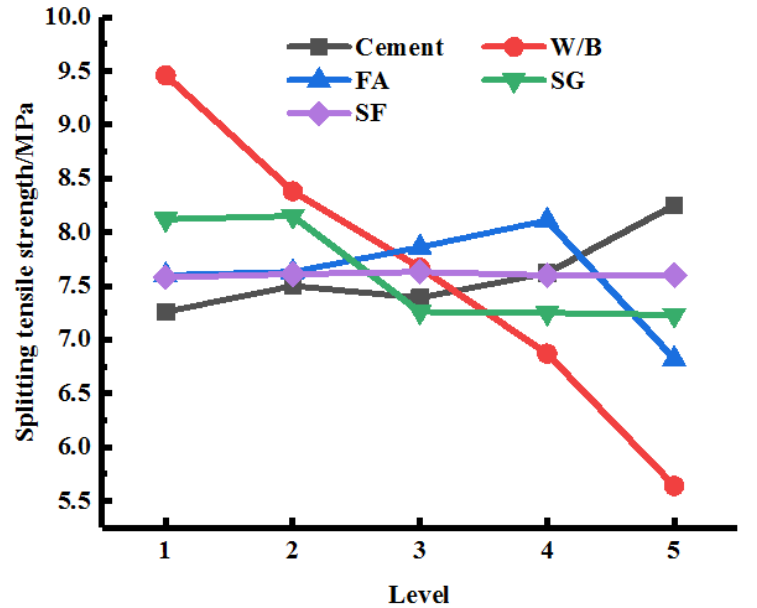

Figure 4. Relationship between factors and splitting tensile strength of hardened cement paste at $28 \mathrm{~d}$.

Table 9. Range analysis of splitting tensile strength of hardened cement paste at $28 \mathrm{~d}$.

\begin{tabular}{|c|c|c|c|c|c|c|}
\hline \multirow{2}{*}{ Level } & \multicolumn{6}{|l|}{$f_{\mathrm{ts}} / \mathrm{MPa}$} \\
\hline & A (Cement) & B (Aggregate) & $\mathrm{C}(\mathrm{W} / \mathrm{B})$ & D FA/ $\%$ & E SG/\% & F SF $/ \%$ \\
\hline $\mathrm{K}_{1}$ & 36.30 & 36.94 & 47.30 & 37.98 & 40.60 & 37.88 \\
\hline $\mathrm{K}_{2}$ & 37.50 & 39.79 & 41.88 & 38.16 & 40.76 & 38.03 \\
\hline $\mathrm{K}_{3}$ & 36.93 & 41.03 & 38.34 & 39.28 & 36.31 & 38.14 \\
\hline $\mathrm{K}_{4}$ & 38.10 & 36.96 & 34.34 & 40.54 & 36.24 & 38.02 \\
\hline $\mathrm{K}_{5}$ & 41.23 & 35.34 & 28.19 & 34.08 & 36.14 & 37.99 \\
\hline $\mathrm{k}_{1}$ & 7.26 & 7.39 & 9.46 & 7.60 & 8.12 & 7.58 \\
\hline $\mathrm{k}_{3}$ & 7.39 & 8.21 & 7.67 & 7.86 & 7.26 & 7.63 \\
\hline
\end{tabular}




\begin{tabular}{lllllll}
\hline \multirow{2}{*}{ Level } & $\boldsymbol{f}_{\text {ts }} / \mathbf{M P a}$ & & & & \\
\cline { 2 - 7 } & $\mathbf{A}($ Cement) & $\mathbf{B}$ (Aggregate) & $\mathbf{C}(\mathbf{W} / \mathbf{B})$ & $\mathbf{D ~ F A / \%}$ & $\mathbf{E ~ S G / \%}$ & F SF/\% \\
\hline $\mathrm{k}_{4}$ & 7.62 & 7.39 & 6.87 & 8.11 & 7.25 & 7.60 \\
$\mathrm{k}_{5}$ & 8.25 & 7.07 & 5.64 & 6.82 & 7.23 & 7.60 \\
$\mathrm{R}$ & 0.98 & 1.14 & 3.82 & 1.29 & 0.92 & 0.05 \\
\hline
\end{tabular}

Note: $\mathrm{K}_{1}, \mathrm{~K}_{2}, \mathrm{~K}_{3}, \mathrm{~K}_{4}$ and $\mathrm{K}_{5}$ represent the corresponding test results when the levels of each factor are 1, 2, 3, 4 and 5, respectively. $\mathrm{k}_{1}, \mathrm{k}_{2}, \mathrm{k}_{3}, \mathrm{k}_{4}$ and $\mathrm{k}_{5}$ represent their average values, respectively. $\mathrm{R}$ represents the range between each factor.

It can be seen from Figure 4 that the five factors affecting the $28 \mathrm{~d}$ splitting tensile strength of hardened cement paste are in the order of water-binder ratio $>$ fly ash content $>$ cement varieties $>$ slag content $>$ silica fume content. The optimal combination obtained by orthogonal test method is: water-binder ratio 0.25 , basic magnesium sulfate cement, slag content $15 \%$, fly ash content $20 \%$ and silica fume content $10 \%$.

\subsection{Range Analysis of Orthogonal Test Results of Interface Test Pieces}

The extreme results of bonding splitting tensile strength of interface test specimens at $28 \mathrm{~d}$ are shown in Table 10 , and the relationship between each factor level and bond splitting tensile strength of interface test specimens at $28 \mathrm{~d}$ is shown in Figure 5.

Table 10. Range analysis of interface bonding splitting tensile strength at $28 \mathrm{~d}$.

\begin{tabular}{|c|c|c|c|c|c|c|}
\hline \multirow{2}{*}{ Level } & \multicolumn{6}{|c|}{ Interface Bonding splitting tensile strength /MPa } \\
\hline & A (Cement) & B (Aggregate) & $\mathbf{C}(\mathbf{w} / \mathbf{b})$ & D FA/ $\%$ & E SG/\% & F SF $/ \%$ \\
\hline $\mathrm{K}_{1}$ & 22.84 & 24.53 & 32.11 & 23.40 & 23.46 & 24.19 \\
\hline $\mathrm{K}_{2}$ & 27.85 & 24.27 & 26.88 & 23.48 & 27.44 & 24.25 \\
\hline $\mathrm{K}_{3}$ & 23.17 & 23.66 & 23.34 & 23.99 & 24.91 & 25.41 \\
\hline $\mathrm{K}_{4}$ & 23.19 & 28.03 & 22.03 & 27.58 & 23.11 & 24.21 \\
\hline $\mathrm{K}_{5}$ & 25.17 & 21.31 & 17.44 & 23.35 & 22.87 & 23.74 \\
\hline $\mathrm{k}_{2}$ & 5.57 & 4.85 & 5.38 & 4.70 & 5.49 & 4.85 \\
\hline $\mathrm{k}_{3}$ & 4.63 & 4.73 & 4.67 & 4.80 & 4.98 & 5.08 \\
\hline $\mathrm{k}_{4}$ & 4.64 & 5.61 & 4.41 & 5.52 & 4.62 & 4.84 \\
\hline $\mathrm{k}_{5}$ & 5.03 & 4.26 & 3.49 & 4.67 & 4.57 & 4.75 \\
\hline $\mathrm{R}$ & 0.99 & 1.34 & 2.93 & 0.85 & 0.91 & 0.33 \\
\hline
\end{tabular}

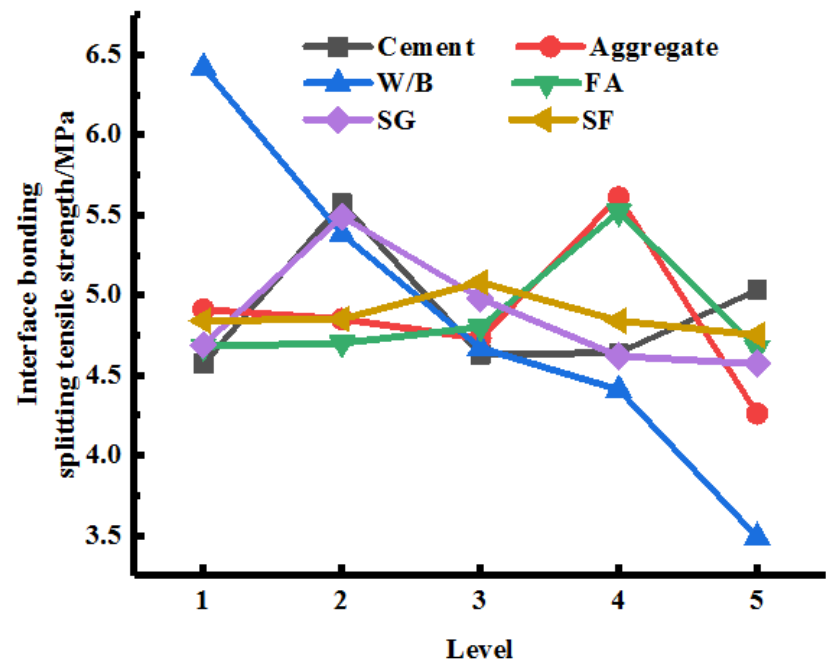

Figure 5. Relationship between factors and interfacial bonding splitting tensile strength at $28 \mathrm{~d}$.

Table 10 shows that the interface bonding splitting tensile strength of 17 \# is the highest, $8.22 \mathrm{MPa}$. The cement variety is $\mathrm{P} \cdot \mathrm{O} 525$ cement, the aggregate is marble, the water-cement ratio is 0.25 , the fly ash content is $20 \%$, the slag content is $35 \%$, and the silica fume content is $5 \%$. Combined with Figure 5 , it can be seen that the influence degree of the six factors affecting the $28 \mathrm{~d}$ bonding splitting tensile strength of the interface specimen is in the order of water-binder ratio $>$ aggregate type $>$ cement type $>$ slag content $>$ fly ash content $>$ silica fume content. The optimal combination obtained by orthogonal test method is: water-cement ratio 0.25 , aggregate is marble, $\mathrm{P} \cdot \mathrm{O} 525$ cement, slag content $15 \%$, fly ash content $20 \%$ and silica fume content $10 \%$.

\section{Relationship Between Interface Strength and Splitting Tensile Strength of Cement Paste}

In order to explore the relationship between the interface strength and the splitting tensile strength of cement paste, Figure 6 is drawn with the splitting tensile strength of hardened cement paste as the abscissa and the interfacial bonding splitting tensile strength as the ordinate. It can be seen that all the test points are below the diagonal line, indicating that the interfacial bonding splitting tensile strength is less than the splitting tensile strength of hardened cement paste, which verifies the conclusion that ITZ is the weakest position in concrete structure. It also can be found that the test points of the same aggregate at different ages are linearly distributed, and the interfacial bonding splitting tensile strength increases with the increase of the splitting tensile strength of hardened cement. By Origin 9.0 fitting, it can be seen that the interface bonding splitting tensile strength and hardening cement paste splitting tensile strength linear correlation is very high, linear 
correlation parameters are shown in Table 11.

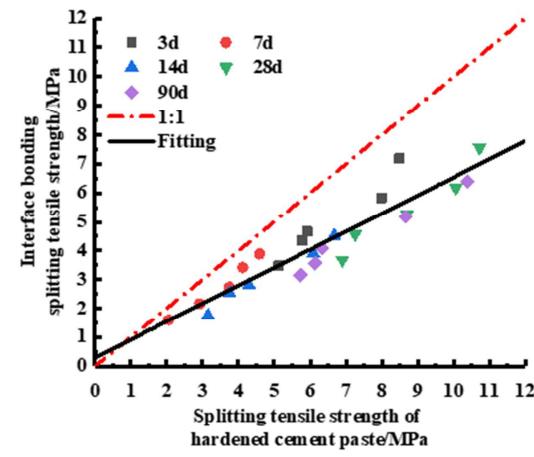

(a) Coral

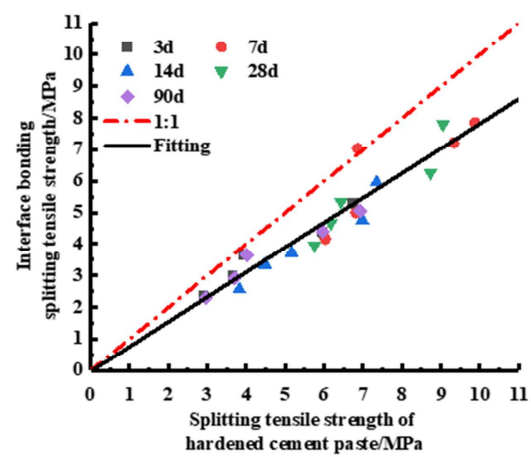

(d) Marble

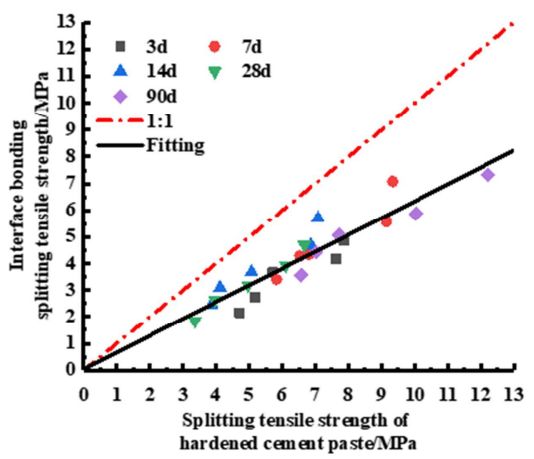

(b) Granite

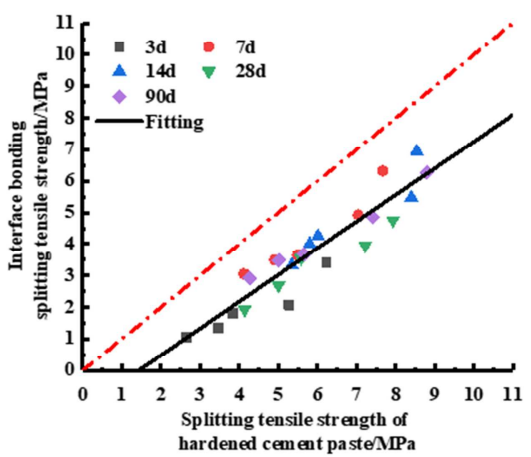

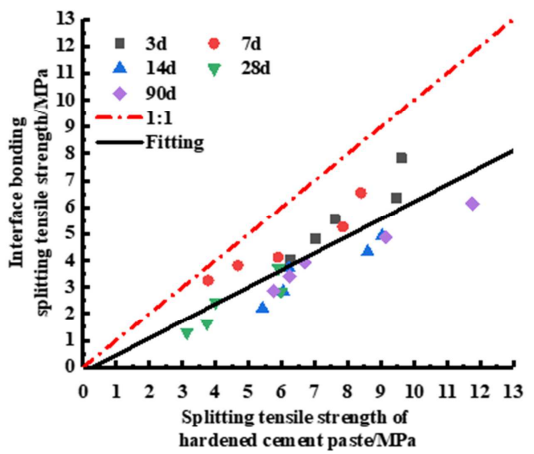

(c) Basalt

\section{(e) Quartzite}

Figure 6. Relationship between interfacial bonding splitting tensile strength and hardened cement paste splitting tensile strength.

Table 11. Linear regression parameters of interfacial bonding strength and paste splitting strength.

\begin{tabular}{llllll}
\hline Aggregate & $\boldsymbol{k}$ & $\boldsymbol{b}$ & $\mathbf{n}$ & $\mathbf{R}^{\mathbf{2}}$ & $\mathbf{R}$ \\
\hline Coral & 0.624 & 0.297 & 25 & 0.871 & 0.933 \\
Granite & 0.631 & 0.034 & 25 & 0.867 & 0.931 \\
Basalt & 0.640 & -0.195 & 25 & 0.719 & 0.848 \\
Marble & 0.785 & -0.028 & 25 & 0.898 & 0.948 \\
Quartzite & 0.847 & -1.208 & 25 & 0.859 & 0.927 \\
\hline
\end{tabular}

The interfacial bonding splitting tensile strength and paste splitting tensile strength are calculated by formula (1) as follows:

$$
f_{\mathrm{ts}, \mathrm{ITZ}}=k \cdot f_{\mathrm{ts}}+b
$$

Where $f_{\text {ts,ITZ }}$ is interfacial bonding splitting tensile strength $(\mathrm{MPa}), f_{\mathrm{ts}}$ is split tensile strength of hardened cement paste (MPa).

Based on the correlation coefficient significance test table in reference, the $\mathrm{R}$ of the fitting formula between the splitting tensile strength of coral, granite, basalt, marble and quartz rock interface specimens and the splitting tensile strength of hardened cement paste are $0.933,0.931,0.848,0.948$ and 0.927 , respectively, which are greater than the critical value of correlation coefficient $\mathrm{R}_{0.001}(25)=0.597$, so the $\alpha$ of the above regression formula is 0.001 ( $99.9 \%$ confidence) [15]. There is a significant linear regression relationship between the interfacial bonding splitting tensile strength and the splitting tensile strength of hardened cement paste.

\section{Conclusion}

(1) The influence degree of five factors on the splitting tensile strength of hardened cement paste is as follows: water-binder ratio $>$ fly ash content $>$ cement variety $>$ slag content $>$ silica fume content. The optimal combination is as follows: water-binder ratio 0.25 , basic magnesium sulfate cement, slag content $15 \%$, fly ash content $20 \%$ and silica fume content $10 \%$.

(2) The order of influence of various factors on the interfacial bonding splitting tensile strength is as follows: water-binder ratio $>$ aggregate type $>$ mud type $>$ slag content $>$ fly ash content $>$ silica fume content. The influence of silica fume content on the interfacial bonding splitting tensile strength is not significant. The optimal combination is: water- binder ratio 0.25 , aggregate is marble, $\mathrm{P} \cdot \mathrm{O} 525$ cement, slag content $15 \%$, fly ash content $20 \%$ and silica fume content $10 \%$.

(3) The splitting tensile strength of interface bonding is less than that of corresponding hardened cement paste, which proves that the interface is the ' weak item ' in concrete. At the same time, the regression model between the splitting tensile strength of interface bonding and the splitting tensile strength of hardened cement paste is established. 


\section{Prospect}

In this paper, orthogonal test was used to explore the influence of various factors on the interfacial bond strength, and the linear regression relationship between the interfacial bond tensile strength and the strength of hardened cement paste was established, but the optimal combination was not verified. Follow-up can be obtained according to the optimal combination of orthogonal test interface ITZ optimal mix; Secondly, the relationship between interfacial bond splitting tensile strength and compressive strength and flexural strength of hardened cement paste is explored, and the database of mechanical parameters of ITZ is established.

\section{Acknowledgements}

The authors gratefully acknowledge the financial support from the National Natural Science Foundation of China under Grant (No. 11832013, No. 51878350, and No. 52078250).

\section{References}

[1] Chen H S, Sun W, Stroeven Piet. Interfacial transition zone between aggregate and paste in cementitious composite (I): Experimental Techniques [J]. Journal of the Chinese Ceramic Society, 2004 (01): 63-69 (in Chinese).

[2] Xie S S. Study on interfacial bonding in cement-based composites [J]. Journal of the Chinese Ceramic Society, 1983 (04): 489-497 (in Chinese).

[3] Wang Y H, Hui H Y, Li Z L. Experiment of mechanics properties of interfacial transition zone between of aggregate and mortar [J]. Concrete, 2020 (01): 19-21 (in Chinese).

[4] Zhu W, Bartosp J M. Application of depth-sensing microindentation testing to study of interfacial transition zone in reinforced concrete $[\mathrm{J}]$. Cement and Concrete Research, 2000, 30 (8): 1299-1304.
[5] Zhu Y C. Experimental investigation on the mechanical properties of mortar-aggregate in Concrete [D]. Dalian University of Technology, 2011 (in Chinese).

[6] Wang Z L, Gu X L, Lin F. Experimental Study on Mechanical Performance of Interface between Mortar and Aggregate in Concrete $[\mathrm{C}] / /$ Workshop on Biennial International Conference on Engineering. 2010: 3529-3536.

[7] Rao G A, Prasad B K R. Influence of the roughness of aggregate surface on the interface bond strength [J]. Cement \& Concrete Research, 2002, 32 (2): 253-257.

[8] Zhou J J, Pan J L, Liang J N, et al. Influence of size effect on bonding performance between coarse aggregate and cement paste [J]. Journal of Building Materials, 2012, 15 (05): 712-716 (in Chinese).

[9] Wang S. Effect of mineral admixture on performance of interface transition zone and pore structure of concrete [D]. Harbin Institute of Technology, 2018 (in Chinese).

[10] Zhang Z Q. Effect of aggregate varieties on mechanical characteristics of hydraulic concrete and numerical simulation of concrete [D]. Changiiang River Scientific Research Institute, 2018 (in Chinese).

[11] Dong Y Y. Experimental study on the mechanical properties of the interfacial zone of cement based composites [D]. Inner Mongolia University of Technology, 2016 (in Chinese).

[12] Lian L. Study on microstructure concrete [D]. Wuhan University of Technology, 2006 (in Chinese).

[13] Hua S. Research on the microstructure and the mechanical property of interface transition zone of coral concrete [D]. Nanjing University of Aeronautics and Astronautics, 2019 (in Chinese).

[14] Gong W, Yu H F, Ma H Y, et al. Mix proportion design and evaluation approach of coral Aggregate seawater concrete [J]. Materials Reports, 2019, 33 (22): 3732-3737 (in Chinese).

[15] D. Mu, Basic Course of Applied Economic Mathematics: Linear Algebra and Probability Statistics, Economic Press China, 1989, pp. 258-268 (in Chinese). 